\title{
Focalización fílmica Clásica y Moderna: estructuras de información en la historia del cine de ficción
}

\author{
Classic and Modern film focalization: information \\ structures in the history of narrative film
}

José Luis VALHONDO-CREGO' (iD) 0000-0003-2383-5513

\section{Resumen}

En el cine de ficción, el espectador extrae la información sobre la trama a partir de la lectura de los estados mentales de los personajes o de suposiciones acerca de las intenciones del autor implícito de la obra. Esa lectura se puede apoyar en las inferencias sobre la conducta de los sujetos o a través de las representaciones del flujo de conciencia de los personajes. Este texto pretende examinar la relación que existe entre la variable mencionada sobre el estado mental y el estilo cinematográfico, Clásico o Moderno. Para ello, emplea datos de Internet Movie Data Base, apuntando a conceptos que remiten a la construcción subjetiva del flujo de conciencia de un personaje, tales como Voice Over, Plano Subjetivo o Flashback. Los resultados, con sus limitaciones metodológicas, se enmarcan en la teoría sobre la Focalización y la Estructura de Información de una trama de ficción. El Cine Clásico recurre a la conducta para inferir los estados mentales de sus personajes, mientras que el Moderno considera la posibilidad de representar audiovisualmente ese flujo de conciencia. El discurso "objetivo" de la "focalización cero" se ajusta mejor a las inferencias sobre la conducta empleadas en el Cine Clásico, mientras que el Cine Moderno se adapta a la subjetividad que se traslada por medio de la focalización interna. Como investigación ulterior, resultaría conveniente descubrir la relación entre el estilo de cine, Clásico o Moderno, y su capacidad para desarrollar la teoría de la mente.

Palabras clave: Cine moderno. Bases de datos. Ficción. Focalización. Teoría de la mente.

\begin{abstract}
In narrative films, viewers extract information about the plot either from reading the characters' mental states or through assumptions about the intentions of the implicit author of the work. This reading can be supported by inferences about the subjects' behaviours or through the representations of the characters' stream of consciousness. This text examines the relationship between the mentioned variable of the mental state and the filmic style - Classic or Modern. It uses the Internet Movie Data Base, pointing to concepts that refer to the subjective construction of a character's consciousness stream, such as Voice Over, Point-of-view hot, or Flashback. The results and their methodological limitations are framed within theoretical debates about the Focalization and Information Structure of a fiction plot. Classic Cinema uses behaviour to infer the characters' mental states, while Modern Cinema considers the possibility of audio-visual representation for such streams of consciousness. The "objective" discourse of "zero focalization" best fits the inferences about behaviour employed in Classic Cinema, while Modern Cinema adapts to the subjectivity expressed by "internal focalization". As further investigation, it would be convenient to discover the relationship between the styles of Cinema, Classic or Modern, and their potential to develop the theory of mind.
\end{abstract}

Keywords: Modern cinema. Data bases. Fiction. Focalization. Theory of mind.

\footnotetext{
1 Universidad de Extremadura, Facultad de Ciencias de la Documentación y la Comunicación, Departamento de Información y Comunicación. Plazuela Ibn Marwan, s/n., 06001, Badajoz, España. E-mail:<jlvalcre@unex.es>.

Recibido el 27 de septiembre de 2019, presentado el 21 de enero de 2020 y aprobado el 7 de abril de 2020.
}

Cómo citar este artículo/How to cite this article

Valhondo-Crego, J. L. Focalización fílmica Clásica y Moderna: estructuras de información en la historia del cine de ficción. Transinformação, v. 32, e190076, 2020. http://dx.doi.org/10.1590/1678-9865202032e190076 


\section{Introducción}

Cualquier film de ficción puede ser considerado una estructura en la que personajes y público perciben y procesan diferente información acerca de los estados mentales de los propios personajes de la trama, es decir, todo film se construye en torno a una estructura de información de diferentes niveles, construida por su productor y decodificada por el público. Esta consideración resuena en la teoría estructuralista y su concepto de "focalización", acuñado por Gérard Genette (1972). Con Genette se formalizó la cuestión de la "focalización" en la Literatura, relacionándola con la diferente información y motivaciones que personajes y espectadores pueden albergar.

Desde el punto de vista del espectador, esa información diferente procede de la consciencia de, y la habilidad para, interpretar los estados mentales de los personajes o del propio autor, lo que se ha venido en llamar dentro de la psicología cognitiva Teoría de la mente (Humphrey, 1993). El espectador da sentido al film a partir de la focalización generada por el autor del estado mental de uno o varios de los agentes de la narración. Dicho de otro modo, el autor coloca el o los focos en diversos puntos de la trama a modo de testigos de la misma; estos pueden coincidir con un personaje, con varios o constituir comentarios del autor. En ese dar sentido al film, el espectador lleva a cabo dos tareas: "leer" los estados mentales de los personajes y representar la mente de un autor implícito (Persson, 2003).

En el contexto del cine de ficción, la información ofrecida al espectador para leer el estado mental de los personajes puede proceder de claves conductuales o cognitivas. El público infiere cogniciones de los personajes a partir de la forma en que se comportan esos personajes o por medio de las representaciones audiovisuales de esas cogniciones directamente (Niederhoff, 2014). No es lo mismo inferir un estado de nerviosismo a través de la acción del sujeto (mostrando su conducta), que hacerlo a partir del recurso de la representación del flujo de pensamiento en forma de "Voice Over", contando su conducta o mostrando imágenes de su estado mental. Este artículo pretende examinar la relación de la variable "Teoría de la mente" con la del estilo cinematográfico, Clásico o Moderno.

La investigación previa se ha centrado en la capacidad de la ficción escrita para estimular y desarrollar la Teoría de la mente (Kidd; Castano, 2013). Además, la evidencia señala diferencias con relación al género audiovisual en cuanto a su desarrollo. En concreto, la ficción, sea literaria o televisiva, sirve mejor al objetivo que el documental (Black; Barnes, 2015). Sin embargo, no existe conocimiento respecto a la relación entre la información ofrecida al espectador para leer el estado mental de los personajes (conductual o cognitiva) y el estilo cinematográfico (Clásico o Moderno). Tampoco se ha examinado el cómo enmarcar esa relación en el esquema sobre el tipo de "focalización" o modo en que se distribuye la estructura de información entre personajes y público (cero o ausencia de focalización, interna y externa).

Para examinar tal relación, se requiere un breve repaso de los conceptos que aplicaremos en aras de clarificar la cuestión de investigación. En primer lugar, el "estado mental" de un sujeto se emplea aquí como el conjunto de percepciones y cogniciones (pensamientos y afectos). Ese estado mental puede ser consciente o inconsciente para el propio sujeto. El personaje puede saber que está nervioso o puede mostrar que lo está sin saberlo; en todo caso, ese estado mental puede comunicarse (aunque a veces el autor decida no hacerlo). En la ficción, el estado mental de un sujeto puede representarse por medio de información sobre su conducta o mediante la representación abierta de pensamientos y sentimientos en imágenes y sonidos. A partir de esa información, el espectador lee o identifica estados mentales.

En segundo lugar, la distinción de estilo cinematográfico Clásico-Moderno parte de dos tradiciones, la evolucionista y la estilística-ideológica (Kovács, 2008). A efectos práctico-metodológicos (revisados más abajo), se recurrirá a la primera, que establece una evolución del lenguaje fílmico en una línea temporal dividida en dos períodos, Clásico y Moderno. Sin embargo, también se tiene en cuenta la tradición estilístico-ideológica que aporta una caracterización de los estilos independientemente del tiempo histórico. Esta tradición relaciona la distinción 
con el concepto de enunciación o autoría. Mientras que el Cine Clásico busca ocultar la huella de su autoría, el Moderno propone desvelar por diversos métodos esa enunciación (Miller, 2008). Esa invisibilización implica un claro contenido ideológico y se expresa por medio de un estilo estético diferente. Se dice que el Cine Clásico creado en Hollywood pretende ser un cine invisible, sin marcas de enunciación (Bordwell, 2012).

En buena lógica, el objetivo es conseguir un estilo que parezca invisible y suscite una ilusión de objetividad, una impresión de que el espectador está observando la realidad misma a través de una ventana, que es la pantalla. Todo discurso contiene por definición marcas de enunciación (Canet; Prósper, 2009). Con "invisible", los teóricos se refieren a las convenciones creativas compartidas y consolidadas entre productores y público que, debidas al hábito de producción y consumo, pueden llegar a pasar desapercibidas para el espectador, que llega a suspender su incredulidad sobre la naturaleza de la ficción (Sánchez-Escalonilla, 2013).

El Cine Clásico ha elaborado una sintaxis que tiende a pasar desapercibida al público por su coherencia a lo largo de la historia del cine. Nöel Bürch (1985) lo llamará Modo de Representación Institucional. Ese Modo incluye criterios relacionados con la continuidad fílmica, emplea estructuras de tres actos o restaurativas (Dacynger; Rush, 2013), observa con disciplina la edición sin saltos de eje, con planos-contraplanos, continuidad lumínica, posiciones de cámara estándar, personajes motivados en tramas con encadenamiento de causas y efectos. Tras varias décadas de perpetuación de estas reglas, su ruptura intencional por parte del autor se relaciona con mostrar la propia enunciación. Por oposición al Clásico, consideramos este cine como Moderno.

De cualquier manera, en los estudios fílmicos, la distinción Clásico-Moderno está consolidada desde Bazin (2005). Existe un consenso entre historiadores de cine a la hora de considerar que el estilo Clásico estándar se consolida alrededor de 1920 y resulta hegemónico hasta la mitad del siglo XX (Kovács, 2008). Gilles Deleuze (1997) abordó el intento más profundo, a la vez que controvertido, de caracterizar lo Clásico frente a lo Moderno. Ese intento se basa en la obra del filósofo Henry Bergson y se centra en la representación del tiempo que cada cine propone en sus tramas. Además, Deleuze incluye un criterio temporal que establece una división entre el cine anterior y posterior a la Segunda Guerra Mundial o, aproximadamente, la mitad del siglo XX (Stam, 2001).

De cara a la metodología se requiere ese criterio temporal que simplifique la cuestión de la definición del estilo, a costa de perder precisión. Tomando como referencia a Deleuze, se considerará Clásico al cine producido hasta aproximadamente la mitad del siglo XX. En adelante, se tratará de Cine Moderno. Como criterio es difuso, pues esa frontera temporal no excluye que el Cine Moderno incluya aspectos clásicos ni viceversa, tal y como indica la tradición estilístico-ideológica.

En tercer lugar, resultaría interesante relacionar estas dos variables (estados mentales y estilo de cine) con el concepto estructuralista de "focalización". Por una parte, para reivindicar el propio concepto para la teoría fílmica desde una nueva perspectiva y, por otra, para establecer futuras cuestiones a analizar relacionadas con el desarrollo de la Teoría de la mente.

En cuarto lugar, este texto exige una aclaración sobre los conceptos de "Voice Over" e "Image Over". El primero está bien definido en el campo de los estudios fílmicos como una voz narrativa superpuesta al discurso audiovisual principal (Kozloff, 1989). Esa voz puede ser empleada como representación del flujo de conciencia del personaje. El Voice Over no pertenece al espacio-tiempo del discurso, pero sí a la historia, según la terminología de Chatman (1978). Del mismo modo que se superpone una Voz, es posible realizar la misma operación con una imagen mental que represente un recuerdo o un deseo del protagonista. Se acuña aquí el término Image Over para designar tal recurso que se emplea, por ejemplo, en los flashbacks de personaje. Esta posibilidad de emplear voces e imágenes sobre el discurso resultaba extraña en la mímesis teatral tradicional. La edición o montaje cinematográfico permite la representación de los estados mentales de formas antes no vistas (Nogueira, 2010). 


\section{Procedimientos Metodológicos}

Se pretende demostrar que el Cine Moderno, por contraste con el Clásico, despliega elementos enfocados a acceder a la conciencia de sus personajes; a representar esa conciencia a través de planos subjetivos, auricularizaciones del pensamiento (Voice Over) y visualizaciones del mismo (lo que se denomina en este texto como Image Over).

Dicho de otro modo, el objetivo consiste en examinar el modo en que las estructuras de información fílmicas han evolucionado a lo largo de la historia del cine, de modo que podemos señalar diferencias claras entre el Cine Clásico o anterior a 1945 y el Cine Moderno, posterior a esa época.

Ese objetivo general se ha desglosado en uno más concreto: analizar el tipo de información que traslada el cine según la lectura de los estados mentales de los personajes. A partir de este objetivo se puede determinar la Hipótesis de trabajo que pretende contrastarse.

Hipótesis: El Cine Moderno incluye un mayor porcentaje de filmes que el Clásico en cuanto al empleo de elementos relacionados con las cogniciones de los personajes (planos subjetivos, auricularizaciones y flahsbacks).

Para contrastar tal hipótesis, se empleó la información alojada en IMDB (Internet Movie Data Base). En concreto, se aborda la cuantificación de variables relacionadas con la exhibición audiovisual de las cogniciones de los personajes. El empleo de IMDB limita el alcance de las conclusiones sobre los resultados, lo que será tratado en el apartado de Discusión. En cualquier caso, IMDB es hoy en día la mayor base de datos mundial sobre cine. Fue puesta en funcionamiento en 1990 y en la actualidad contiene datos sobre más de seis millones y medio de títulos, entre películas, cortometrajes y episodios de series televisivas (Internet ..., 2020).

Internet Movie Data Base permite al usuario realizar búsquedas de títulos restringiendo los valores a períodos de tiempo, géneros o características tales como la presencia de planos subjetivos, flashbacks, etc. A partir de esa funcionalidad, se pudo comparar, en primer lugar, la presencia de flashbacks y flashforwards en el Cine Clásico y en el Moderno. En segundo lugar, se cuantificaron las diferencias con relación al número de planos subjetivos en ambos estilos. En tercer lugar, se trató la variable Voice Over como expresión de los pensamientos de un personaje.

\section{Resultados}

Los resultados indican que existen claras diferencias cuantitativas con relación a las variables seleccionadas para representar el estado mental de los personajes. Se desglosan esos resultados a continuación.

\section{Flashbacks/flashforwards}

La presencia de flashbacks o flashforwards en una producción fílmica denota la intención del autor de representar de modo literal la vida mental del personaje. En rigor, la definición mencionada hace referencia al flashback de personaje, por contraste con el flashback de trama. El primero está motivado desde el personaje, el segundo desde el autor.

El Cine Clásico empleó el recurso del flashback en una proporción menor que el Moderno (Tabla 1). En porcentajes, por cada mil películas estrenadas, no llegan a dos las que contenían un flashback. En el Cine Moderno esta cifra se multiplica casi por diez. Además, la naturaleza del flashback moderno ya no solo atiende a la motivación de la memoria de un personaje, sino que también se relaciona con la necesidad del autor de saltar hacia atrás en la trama. Es decir, se trata de un flashback del autor/trama frente al del protagonista. 
Tabla 1. Número de filmes con flashbacks y flashforward.

\section{Planos subjetivos}

Una búsqueda de filmes con planos subjetivos arroja un resultado revelador. En la época que consideramos como Cine Clásico (1900-1945), encontramos solo seis películas que incluyen este tipo de plano, frente a las 886 que se indican para el período moderno (Tabla 2).

\section{Auricularización de cogniciones}

Antes de 1945 solo existen tres películas que incluyen una voz interna para los pensamientos de un personaje (y una es de animación). A partir de 1945, aparecen más de 150 (Tabla 3). En el paradigma clásico no estaba de moda la auricularización del pensamiento interno. El pensamiento como tal no era objeto de focalización. En general, la narración en Voice Over es menos corriente en el Cine Clásico, incluso en números relativos a la cantidad de películas estrenadas. Es cierto que la Voice Over también se emplea para narrar la acción y, en este caso, la diferencia no es tan abultada en porcentaje.

Tabla 2. Número de filmes con planos subjetivos.

\begin{tabular}{lccc}
\hline \multirow{2}{*}{ Periodo temporal } & No filmes estrenados & \multicolumn{2}{c}{ Planos subjetivos } \\
\cline { 3 - 4 } & & $\mathrm{n}$ & $\%$ \\
\hline $1900-1945$ & 174.804 & 6 & 0.00003 \\
$1946-2019$ & 895.037 & 886 & 0.0009 \\
\hline
\end{tabular}

Fuente: Elaborado por el autor (2020).

Tabla 3. Número de Filmes con Voice-over para narración o expresión de pensamientos.

\begin{tabular}{|c|c|c|c|c|c|}
\hline \multirow{3}{*}{ Periodo temporal } & \multirow{3}{*}{ No filmes estrenados } & \multicolumn{4}{|c|}{ Voice Over } \\
\hline & & \multicolumn{2}{|c|}{ (Narración) } & \multicolumn{2}{|c|}{ (Pensamientos) } \\
\hline & & $\mathrm{n}$ & $\%$ & $n$ & $\%$ \\
\hline 1900-1945 & 174.804 & 257 & 0.14 & 3 & 0.00001 \\
\hline 1946-2019 & 895.037 & 5.497 & 0.61 & 169 & 0.0001 \\
\hline
\end{tabular}

Fuente: Elaborado por el autor (2020).

\section{Discusión}

Los resultados apuntan a que el Cine Clásico propone al espectador representar los estados mentales de sus personajes a partir de la forma en que actúan, mientras que el Moderno también considera la posibilidad de 
representar esa percepción, motivaciones y creencias de modo directo, a través de su representación visual y auditiva.

¿Cómo se puede enmarcar este resultado con relación al concepto de focalización o estructura de información de la trama? Gérard Genette (1972) discriminaba tres modos de focalización: cero, interna y externa. Con la focalización cero describía un relato en el que el narrador disfrutaba de una mente omnisciente, conectada con el espectador a través de los personajes. La focalización cero implicaba objetividad, el triunfo de la racionalidad y el punto de vista neutral que, en apariencia, no privilegia ningún punto de vista. Dicho de otro modo, la expresión "cero" denota que el foco no se coloca en ningún agente en especial y sí en todos.

Dicha focalización perseguía crear la impresión de una mente única que uniera a personajes y público bajo la tutela de una autoridad objetiva que regulaba el acceso del espectador a una descripción "ajustada a la realidad". Genette se sirvió del término de Roland Barthes (1968) sobre "grado de escritura cero", que venía a representar la objetividad hecha escritura neutral o, mejor dicho, la convención ilusoria de una escritura neutral, fruto de la idea y herencia del discurso científico documental y de la idea simbólica de perspectiva lineal omnisciente (Panofsky, 1983). Ni la pintura ni el teatro, como formas artísticas miméticas predecesoras del cine, representaban los estados mentales de los sujetos. Y la literatura solo comenzó a hacerlo a partir de la Modernidad de escritores como Joyce, cuando se plantearon representar el flujo de conciencia. Precisamente, las técnicas de Joyce se emparentan con el cine (Burkdall, 2018).

En estas artes, la posición del ojo omnisciente del autor durante el proceso creativo se replicaba más tarde por el espectador del cuadro o el público de la platea. Ese público actualizaba la posición de omnisciencia o focalización cero del autor. Y los teóricos convergen al afirmar que el cine se desarrolló tomando prestados esos axiomas del teatro y la pintura (Bordwell, 1985). De hecho, el cine comenzó siendo un plano fijo de una representación teatral. El Cine Clásico, como en su momento la pintura al óleo, pretendía invisibilizar la hegemonía de su propio modo de representación, haciéndolo pasar como "natural". En resumen, el estilo Clásico coloca al espectador como ojo omnisciente de la trama que disfruta de una perspectiva superior a cualquiera de los personajes e infiere información sobre ellos a partir de la observación de la conducta.

Genette (1972) también habló de "focalización interna" para indicar un tipo de narración en la que el espectador sabe tanto como uno de los personajes. El público es orientado hacia el protagonista de la trama, del que puede leer en algún grado su mente a través de la representación directa de sus cogniciones. Del resto de los personajes ese grado de lectura es siempre menor.

Si ese grado de conocimiento es mínimo o nulo, Genette propone un tercer caso, la "focalización externa", en el que la Teoría de la mente no alcanza su objetivo y se cortocircuita la comunicación interpersonal. En él, el autor viene a (meta)comunicar al lector que leer los estados mentales de alguien es una tarea vana. Incluso, se colige que llega a poner en duda que uno pueda entender sus propios estados mentales, por lo que es imposible que alguien los lea desde fuera, aunque exista la compulsión a realizarlo. El espectador sabe menos que el protagonista porque el autor adopta la postura de negar que sea posible entender los estados mentales ajenos o, incluso, los propios.

Respecto al tipo de información analizada, la utilización de IMDB en este estudio implica una serie de limitaciones que deben declararse. Los datos proporcionados por IMDB podrían ser considerados como el resultado de un Análisis de Contenido de los filmes. Se trataría de un análisis realizado por miles de usuarios que no comparten unas reglas de codificación comunes y coherentes. No están entrenados en la codificación y las categorías o códigos empleados. Tampoco siguen los procedimientos propios establecidos por el análisis cualitativo. Las categorías que se emplean no atienden a un proceso de refinamiento, por lo que no tienen por qué ser categorías excluyentes; puede haber solapamientos de categorías. También es cierto que, una vez establecida una categoría clara como flashback, un mayor número de codificadores garantiza un menor error. De cualquier manera, el procedimiento empleado serviría como mínimo de modo exploratorio para nuevas hipótesis. 
En especial, parece interesante para estudios ulteriores relacionar estos resultados con los hallazgos sobre la diferente capacidad del estilo Clásico o Moderno en la estimulación de la Teoría de la mente del espectador. Como se señalaba antes, la investigación previa ha explorado la influencia del género fílmico, pero no así del estilo. Se podría esperar que el Cine Clásico pudiera contribuir a un mayor desarrollo de la Teoría de la mente, por cuanto el espectador debe hacer uso de su capacidad para inferir estados mentales a partir de la conducta de los personajes. De cualquier modo, también resulta plausible pensar que los factores culturales asociados al consumo de uno u otro estilo de Cine podrían influir en la variable Teoría de la mente.

\section{Conclusiones}

Salvando las limitaciones metodológicas, este estudio revela que el Cine Clásico se caracteriza por mostrar el estado mental de los personajes a partir de sus conductas observables, mientras que el Moderno lee ese estado mental a partir de un personaje a cuyo estado mental se puede acceder directamente por lo que ve, escucha, siente o piensa. Así lo atestigua el aumento del uso del plano subjetivo, la auricularización u ocularización de los estados mentales de los personajes en el período considerado propio del Cine Moderno.

No debe ignorarse que estas conclusiones no solo se aplican al estado mental de los personajes sino también al del autor implícito que el espectador infiere tras la trama. El público imagina una mente que ordena y hace progresar la trama. Lo que se aplica al personaje también puede extenderse al autor.

La posibilidad de representar los estados mentales de modo audiovisual era técnicamente imposible en un medio como el teatro. Solo el montaje cinematográfico permite esa posibilidad. Sin embargo, el Cine Clásico focaliza su atención en claves de conducta y no es hasta la llegada del Cine Moderno cuando el espectador comienza a disfrutar de "visualizar" lo que hay en la mente de los personajes.

El Cine Clásico construye un tipo de realismo a partir de la conducta, lo que concuerda en mayor medida con la "focalización cero"y su discurso de objetividad. Esa ilusión de objetividad también se ajusta al intento del Cine Clásico de invisibilizar la enunciación. Por su parte, el Cine Moderno incorpora la posibilidad del descentramiento del sujeto, es decir, de una visión de la trama subjetiva con la que se identifica el espectador. En el Cine Moderno, el autor restringe la cantidad de información que recibe el público y profundiza en la representación inequívoca de los estados mentales.

Desde la perspectiva metodológica, merece la pena considerar las posibilidades de una fuente de información como IMDB de cara al escrutinio sobre cuestiones de Narrativa Audiovisual.

En investigaciones ulteriores, se pretende examinar cómo influye el estilo del cine en el desarrollo de la Teoría de la mente. Las evidencias demuestran que el género de ficción es superior en este sentido al documental. Se trataría de comprobar si el Cine Clásico sirve mejor a tal propósito que el Cine Moderno.

\section{Referencias}

Barthes, R. Elements of semiology. New York: Hill and Wang, 1968.

Bazin, A. What is cinema? London: University California Press, 2005.

Black, J.; Barnes, J. L. Fiction and social cognition: the effect of viewing award-winning television dramas on theory of mind. Psychology of Aesthetics, Creativity, and the Arts, v. 9, n. 4, p. 423-429, 2015. Doi: http://dx.doi.org/10.1037/aca0000031

Bordwell, D. Narration in the fiction film. Madison: University of Wisconsin Press, 1985.
Bordwell, D. Poetics of cinema. New York: Routledge, 2012. Doi: http://dx.doi.org/10.4324/9780203941898

Bürch, N. Praxis del cine. Madrid: Fundamentos, 1985.

Burkdall, T. Joycean frames: film and the fiction of James Joyce. New York: Routledge, 2018. Doi: http://dx.doi.org/10.43 24/9780203815021

Canet, F.; Prósper, J. Narrativa audiovisual: estrategias y recursos. Madrid: Síntesis, 2009. 
Chatman, S. B. Story and discourse: narrative structure in fiction and film. Ithaca: Cornell University Press, 1978.

Dacynger, K.; Rush, J. Alternative scriptwriting: rewriting the hollywood formula. Burlington: Taylor \& Francis, 2013.

Deleuze, G. Cinema 2: the time image. Minneapolis: University of Minnesota Press, 1997.

Genette, G. Discours du récit: figures III. Paris: Seuil, 1972.

Humphrey, N. La mirada interior. Barcelona: Alianza Editorial, 1993.

Internet Movie Data Base. IMDb Home Page. Seattle: IMDb, 2019. Available from: https://www.imdb.com/pressroom/stats/ Access: 27 dec. 2019.

Kidd, D. C.; Castano, E. Reading literary fiction improves theory of mind. Science, v. 342, n. 6156, p. 377-380, 2013. Doi: http:// dx.doi:10.1126/science.1239918

Kovács, A. B. Screening modernism: European art cinema, 1950-1980. Chicago: The University of Chicago Press, 2008. http://dx.doi.org/10.7208/chicago/9780226451664.001.0001
Kozloff, S. Invisible storytellers: voice-over narration in American fiction film. Los Angeles: University of California Press, 1989.

Miller, T. From creative to cultural industries. Cultural Studies, v. 23, 1, p. 88-99, 2008. http://dx.doi.org/10.1080/09502380 802326660

Niederhoff, B. Perspective: point of view. In: Hühn, et al. (ed.). Handbook of narratology. Berlín: Walter de Gruyter, 2014, p. 692-705. Doi: http://dx.doi.org/10.1515/9783110 316469.692

Nogueira, L. Planificaçao e montagem. Covilhã: Livros LabCom., 2010.

Panofsky, E. Meaning in the visual arts. Chicago: The University of Chicago Press, 1983.

Person, P. Understanding cinema: a psychological theory of moving imagery. Cambridge: Cambridge University Press, 2003.

Sánchez-Escalonilla, A. Estrategias de guión cinematográfico: el proceso de creación de una historia. Barcelona: Ariel, 2013.

Stam, R. Teorías del cine: una introducción. Barcelona: Paidós Comunicación, 2001. 